\title{
Previdência social, acidente de trabalho e nexo técnico epidemiológico
}

\author{
Rita Franco Rego \\ Edriene Barros Teixeira \\ Denismar Borges de Miranda \\ Paulo Gilvane Lopes Pena
}

\section{SciELO Books / SciELO Livros / SciELO Libros}

REGO, R.F., TEIXEIRA, E.B., MIRANDA, D.B., and PENA, P.G.L. Previdência social, acidente de trabalho e nexo técnico epidemiológico. In: FERNANDES, R.C.P., LIMA, M.A.G., and ARAÚJO, T.M., comps. Tópicos em saúde, ambiente e trabalho: um olhar ampliado [online]. Salvador: EDUFBA, 2014, pp. 239-267. ISBN: 978-65-5630-012-2. https://doi.org/10.7476/9786556300122.0012. \section{International license.}

All the contents of this work, except where otherwise noted, is licensed under a Creative Commons Attribution 4.0

Todo o conteúdo deste trabalho, exceto quando houver ressalva, é publicado sob a licença Creative Commons Atribição $\underline{4.0}$. 


\section{Previdência social, acidente de trabalho e nexo técnico epidemiológico}

Rita Franco Rego

Edriene Barros Teixeira

Denismar Borges de Miranda

Paulo Gilvane Lopes Pena

\section{Introdução}

A Previdência Social instituiu, em 2006, o Nexo Técnico Epidemiológico Previdenciário - NTEP. Com a adoção do NTEP foi implantada uma nova metodologia para concessão dos benefícios previdenciários por acidentes de trabalho e doenças ocupacionais, baseada no cruzamento das informações relativas a dados ocupacionais e de saúde dos trabalhadores, apontando a possibilidade de nexo entre doença e trabalho.

O objetivo deste capítulo é: analisar aspectos relativos à evolução da Previdência Social no Brasil, com ênfase no processo de notificação de acidentes de trabalho e a adoção do NTEP; estabelecimento do nexo entre doença e trabalho no âmbito da Previdência Social, Seguro de Acidentes de Trabalho e sua relação com NTEP; a implantação do NTEP sob a perspectiva da Gestão da Informação; e destacar a importância da adoção do NTEP no contexto da implementação da Política Nacional de Saúde do Trabalhador.

\section{O nexo técnico epidemiológico e a previdência social no Brasil}

Conforme a legislação previdenciária, acidente do trabalho é aquele que ocorre pelo exercício do trabalho a serviço da empresa 
provocando lesão corporal ou perturbação funcional que cause morte, perda ou redução da capacidade para o trabalho permanente ou temporária. (BRASIL, 1992) Os acidentes de trabalho se manifestam de forma abrupta, muitas vezes causando sequelas e mesmo a morte de trabalhadores, contribuindo de forma considerável para as estatísticas de mortalidade por causas externas (causas violentas de morte), acometendo principalmente indivíduos do sexo masculino e em idade produtiva. As causas mais comuns de óbito por acidente são politraumatismos, queimaduras, intoxicações, etc. Já doença ocupacional, profissional ou do trabalho tem conotações com diferentes sentidos, mas para efeito da presente análise, serão tomadas como sinônimas. As doenças do trabalho são entidades nosológicas que acometem pessoas que vivenciam formas de inserção no processo produtivo de bens e serviços. No Brasil atualmente são reconhecidas oficialmente em torno de 200 patologias relacionadas ao trabalho. (BRASIL, 2001) Para efeito securitário, a previdência equipara acidente do trabalho com doença do trabalho. Nesse sentido, a presente análise abordará esses conceitos segundo essa lógica previdenciária para construir a conexão do desenvolvimento institucional.

No Brasil, uma parte substancial dos custos diretos com acidentes e doenças do trabalho recai sobre o Ministério da Previdência Social (MPS) que, por meio do Instituto Nacional do Seguro Social (INSS), tem a missão de garantir o direito previdenciário. (SANTANA et al., 2006) Os benefícios previdenciários destinam-se a pagamentos dos segurados e seus dependentes quando da perda da capacidade laboral do trabalhador. Desta forma, os acidentes e as doenças do trabalho constituem eventos de grande relevância social e econômica. De acordo com dados econômicos previdenciários, o valor total gasto com benefícios em 2006 atingiu R \$2,45 bilhões, e em 2007 alcançou cerca de R \$ 2,57 bilhões. (BRASIL, 2007a) No total dos gastos estão incluídos todos os benefícios previdenciários como: auxílio-doença acidentário, auxílio acidente, aposentadoria por invalidez acidentária, entre outros. Em 2006, a espécie de benefício com maior valor médio foi aposentadoria por invalidez acidentária, correspondendo a R \$1.020,04. Em 2007, foi aposentadoria por tempo de contribuição, equivalente a $\mathrm{R} \$ 1.073,90$, em seguida a aposentadoria por invalidez acidentária, com valor médio de $\mathrm{R} \$ 993,99$. (BRASIL, 2007a) Destaca-se, que as aposentadorias 
acidentárias estão relacionadas a acidentes e/ou doenças relacionadas ao trabalho que constituem eventos passíveis de ações de prevenção. A alta frequência de AT grave também tem forte impacto sobre a assistência à saúde, pois contribuem para a demanda dos serviços especializados, ocupação hospitalar incluindo leitos de UTI, tratamento clínico ambulatorial, serviços de reabilitação fisioterápica ou de atendimento psicoterápico por tempo prolongado. (SANTANA et al., 2009) Em geral, estas ações são custeadas pelo Ministério da Saúde (MS).

Os agravos à saúde do trabalhador conectam-se intrinsecamente com problemas vividos hoje pela sociedade brasileira nos grandes centros urbanos. As associações entre acidentes de trabalho e mortes violentas se tornam cada vez mais estreitas. No conjunto das causas externas, os acidentes de transporte relacionados ao trabalho, acidentes típicos ou de trajeto, destacam-se pela magnitude das mortes e incapacidade parcial ou total, permanente ou temporária, envolvendo trabalhadores urbanos e rurais. (BRASIL, 2001)

Deste modo, cabe à Previdência Social a identificação do nexo entre trabalho e agravo, além da compensação salarial através de benefícios previdenciários para os casos que necessitem de afastamento do trabalho. Assim, as informações provenientes dos registros previdenciários constituem um importante banco de dados sobre acidentes e doenças do trabalho. Entretanto, no Brasil, a subnotificação desses eventos constitui um fator limitante, tanto do ponto de vista jurídico quanto social, pois retira a garantia de direitos trabalhistas dos indivíduos acidentados e dificulta a implementação de políticas públicas.

Os registros sistemáticos de acidentes e doenças relacionadas com o trabalho, entre trabalhadores do mercado formal no Brasil, se iniciaram na década de 70 e, desde então, sofrem a influência de vários fatores econômicos, políticos e sociais, dentre os quais se destacam: sonegação da notificação por parte dos empregadores, mudanças na legislação, alterações no processo produtivo que inclui as transformações nos padrões de emprego. Estes fatos sempre constituíram um obstáculo para o planejamento e implantação de políticas de prevenção. Antes da adoção do NTEP a notificação de acidentes e doenças do trabalho, no âmbito previdenciário, dependia quase que exclusivamente da emissão da Comunicação de Acidente do Trabalho (CAT). As estatísticas oficiais brasileiras sobre acidentes e doenças do trabalho também eram 
elaboradas a partir das informações obtidas pela CAT, a ocorrência do acidente era registrada e reconhecida oficialmente após a CAT, estabelecendo-se o direito do trabalhador ao beneficio previdenciário acidentário junto ao INSS. Porém, o fluxo da CAT, até seu registro no INSS encontrava muitos entraves, pois a emissão da CAT dependia, em grande parte, de ato voluntário do empregador. (CORDEIRO; SAKATE; CLEMENTE, 2005) Com a adoção do NTEP, a notificação do acidente, no âmbito da Previdência Social (PS), passou a não depender exclusivamente da CAT.

No Brasil, a escassez de estudos relacionados aos acidentes e doenças ocupacionais, com objetivo de promover ações de pesquisa, vigilância, assistência, promoção, proteção e reabilitação da saúde do trabalhador, sempre dificultaram a elaboração de políticas públicas previdenciárias e intersetoriais. A ausência de dados previdenciários consistentes constitui um empecilho frequente porque dificulta a identificação e o dimensionamento de fontes de custeio que envolve políticas públicas relacionadas ao menos a três ministérios: da Previdência Social, que financia ações da Seguridade Social através do INSS; Ministério da Saúde, que financia ações de saúde por meio do Sistema Único de Saúde (SUS); e Ministério do Trabalho e Emprego (MTE), com ações de fiscalização do trabalho por parte das Superintendências Regionais do Trabalho (SRT).

O NTEP pode contribuir para a identificação de novos fatores de risco para acidentes cujo nexo causal ainda não foi estabelecido. Como, por exemplo, nos casos de acidentes relacionados às mudanças no processo produtivo. Um exemplo destas alterações na produção é a constante incorporação da informática e da robótica aos processos de trabalho, que vem ocasionando o deslocamento da força de trabalho do setor secundário para o terciário, criando deste modo, um novo padrão de fatores de risco ocupacionais. O desdobramento desses riscos em agravos resultaria na elevação da frequência dessas patologias e isso se transformaria em indicador de frequência da nova patologia emergente. 


\section{Evolução da previdência social brasileira, sua relação com a adoção do nexo técnico epidemiológico e com a notificação de acidente de trabalho}

O trabalho e suas consequências para a saúde, em especial o acidente e a doença, são descritos desde os primórdios da humanidade. O trabalho pode ser considerado um instrumento de integração social, sendo um meio de sobrevivência e de interação social. Não há dúvida que o trabalho ocupa lugar fundamental na inserção social dos indivíduos, no seu adoecer e morrer. (BRAGA, 2000) Por este motivo, examinar o curso da evolução histórica da notificação do acidente de trabalho torna-se fundamental para compreender a estrutura das normas jurídicas atuais, que amparam o sistema de proteção e reparação aos trabalhadores, em especial a seguridade social.

As relações entre saúde humana e trabalho são alvo de avaliação e estudo das mais diversas áreas do conhecimento científico. No âmbito da medicina, as primeiras associações entre trabalho e saúde surgiram na antiguidade, mas apenas em 1700, Bernardino Ramazzini relacionou um amplo leque de profissões com os problemas de saúde dos trabalhadores, valorizando a importância da ocupação para o diagnóstico e tratamento das patologias. (RAMAZZINI, 1999) Os trabalhos de Ramazzini (1999) foram considerados marco inicial da medicina do trabalho. Todavia a medicina do trabalho, enquanto especialidade médica, só surgiu na Inglaterra na primeira metade do século XIX, com a Revolução Industrial e a criação do primeiro serviço de medicina do trabalho, em 1830. (MENDES, 2005) No século XIX pós-revolução industrial, o trabalho sofreu transformações importantes, passando a ser separado de outras atividades e esferas sociais. Foi possível a separação entre a esfera doméstica e a esfera da produção, a divisão entre propriedade privada e o trabalho assalariado. Assim, surgiram novas formas de produzir e com elas novas formas de adoecer e morrer relacionadas ao trabalho. (OFFE, 1989) Foi neste contexto que as doenças do trabalho e os acidentes do trabalho se ampliaram e passaram a assumir relevância em saúde pública e a fazer parte da vida dos trabalhadores.

A primeira legislação que tratou do tema acidente do trabalho e reparação previdenciária na esfera da organização estatal foi o plano 
de Previdência aos acidentes de trabalho, que surgiu na Alemanha, em 1883, com Otto Von Bismarck. (CARNEIRO, 2008) Em 1886, na Itália, surgiram as organizações de amparo mútuo, que eram associações voluntárias de operários, baseadas na solidariedade dos contribuintes. Nestas associações os operários contribuíam para ter direito a benefícios devidos à doença, invalidez ou idade avançada. Também eram concedidos por estas associações benefícios aos familiares dos associados falecidos. Por conta das dificuldades econômicas e problemas inerentes a este sistema, estas associações terminaram em decadência. Por este motivo, em 17 de março de 1898, na Itália, surgiu à lei que tornou obrigatório, por parte dos empregadores das indústrias, o seguro para acidente relacionado ao trabalho, e esta lei constituiu o nascimento do sistema previdenciário italiano.

No Brasil, no século XIX, com a industrialização das grandes cidades, especialmente São Paulo e Rio de Janeiro, começaram a aumentar a frequência de doenças e acidentes relacionados ao trabalho. Deste modo, a evolução do sistema previdenciário não seguiu um caminho diferente, tendo, primeiramente, passado pela simples caridade, pelo mutualismo de caráter privado e facultativo, e, depois, pelo seguro social. Em 1919, foi promulgado o Decreto Legislativo $n^{\circ} 3.724$, que regulamentou o seguro para acidente do trabalho, o qual tratava da proteção aos trabalhadores, iniciando-se, no Brasil, a responsabilização do empregador pela indenização ao trabalhador acidentado, ficando a cargo da polícia a função de registrar tais acontecimentos. (CORDEIRO; SARATE; CLEMENTE, 2005) A regulamentação do Seguro Acidente de Trabalho (SAT) representava, na época, uma influência do direito europeu nas relações de trabalho, em que se difundiu a teoria do risco profissional e caracterizava, no Brasil, o início de um novo regime de responsabilidade civil do empregador para com seus funcionários acidentados. O SAT representou o surgimento, no direito brasileiro, de um dos primeiros sistemas de direito social, pois refletia a necessidade de proteção à saúde dos trabalhadores à época. (SANTOS, 2007)

O Decreto $n^{\circ} 3.724$ foi acompanhado da edição da Lei $n^{\circ} 4.682$, de 24 de janeiro de 1923, chamada "Lei Eloy Chaves", que criou as Caixas de Aposentadorias e Pensões dos Ferroviários - CAPs. (BRASIL, 1923) Estas funcionaram, em todo o território nacional, instituindo seguro social a funcionários públicos, e eram baseadas em premissas de 
solidariedade ampla entre os trabalhadores. A partir desta lei, os empregados ferroviários passavam a contar com uma instituição previdenciária que oferecia os seguintes benefícios: aposentadoria por tempo de serviço, aposentadoria por conta de doenças e acidentes (invalidez), pensão, assistência médica e assistência farmacêutica. (CORDEIRO; SARATE; CLEMENTE, 2005)

A implantação da "Lei Eloy Chaves" representou um capítulo relevante na evolução da previdência social no Brasil, pois aceleradamente se acentuou o caráter público da tutela previdenciária, a qual, originalmente voluntária, tornou-se obrigatória, condicionada ao cumprimento das obrigações arcadas pelo empregador. A evolução previdenciária avançava favorecida pela transformação das estruturas econômicas e, posteriormente, na década de 30, durante o governo Getúlio Vargas, passou a vigorar o regime dos institutos com início da montagem de um sistema público de Previdência Social no Brasil, de modo a responder ao dinamismo político e econômico do processo de industrialização. Proliferam, assim, os Institutos de Aposentadoria e Pensões (IAPs), que eram restritos aos trabalhadores urbanos, porém agora se organizavam por categoria profissional e não mais por empresa.

Deste modo, todos os profissionais de uma mesma categoria estavam qualificados para receber os mesmos benefícios, independe da empresa à qual estivessem ligados. Além disso, a administração dos IAPs não ficava mais a cargo de empregados e patrões, como nas CAPs, o governo passou a ser parte integrante do sistema e o presidente da República nomeava o presidente de cada IAP. O sistema de contribuição passou a ter o seu comando político estabelecido por meio do sistema tripartite, formado por: estado, empregador e empregado. O custeio vinculava-se obrigatoriamente às três fontes, ocorrendo, assim, a efetivação da tutela previdenciária a entidades públicas adequadamente instituídas. (CORDEIRO; SARATE; CLEMENTE, 2005) Entretanto, a despeito dos avanços, um amplo contingente de trabalhadores ainda permanecia excluído desta tutela previdenciária, dentre os quais se destacam os autônomos, os trabalhadores domésticos e todos os trabalhadores rurais que na época, ainda eram maioria.

Um marco importante relacionado à reparação previdenciária por conta dos acidentes e doenças do trabalho ocorreu com a promulgação da Lei $n^{\circ} 7.036$, em 1944, que trouxe importantes modificações, intro- 
duzindo o conceito de concausalidade. (BRASIL, 1944) No âmbito da legislação previdenciária, a causa é toda condição sem a qual o resultado não teria ocorrido, ou ainda, a totalidade das condições positivas e negativas que contribuíram para a produção do acidente. A concausa é outra causa que, associada à principal, concorre para determinado desfecho. As concausas, por si só, não iniciam e nem interrompem o processo causal, apenas o reforçam, ou seja, a concausa determina a possibilidade da lesão dever-se não somente ao acidente, mas também, a fatores preexistentes, concomitantes ou sucedidos. Se existem concausas, o acidente poderá produzir lesões diversas ou mais graves. As concausas podem ser classificadas como: preexistentes, se a causa existe antes da ocorrência do acidente; concomitantes, se ocorre no momento do acidente; supervenientes, se ocorre depois do acidente.

Associada à definição de concausalidade, a Lei n ${ }^{\circ}$ 7.036/44 ampliou o conceito de acidente do trabalho para fins de reparação, equiparando-o a doença resultante das condições de trabalho ao acidente. (BRASIL, 1944) Estabeleceu, com isso, a distinção entre doenças profissionais, que são inerentes a determinados ramos de atividade, e doenças do trabalho, que são resultantes das condições especiais ou excepcionais em que o trabalho é realizado. Esta Lei, do mesmo modo, consagrou o conceito do acidente de trajeto.

Assim, com a Lei $\mathrm{n}^{\circ} 7.036 / 44$, a tutela dos acidentes foi definitivamente estendida aos acidentes ocorridos durante o percurso de ida e retorno da residência ao local de trabalho, às doenças profissionais e às doenças do trabalho. (CORDEIRO; SARATE; CLEMENTE, 2005) Posteriormente, o Decreto-Lei $n^{\circ} 7.036 / 44$ foi também relevante, por universalizar o seguro obrigatório contra acidente de trabalho.

Com a promulgação da Lei Orgânica da Previdência Social (LOPS), em 1960, ocorreu uma importante evolução no âmbito da reparação previdenciária, pois foram uniformizadas as contribuições e os planos de previdência com extensão da cobertura previdenciária aos empregadores e autônomos em geral. (BRASIL, 1960) O que veio a se consolidar em 1966, com a criação do Instituto Nacional de Previdência Social (INPS), que unificou a estrutura dos IAP. O INPS passou a se responsabilizar pelas aposentadorias, pensões e pela assistência médica de todos os trabalhadores do mercado formal e seus dependentes, com exceção do funcionalismo da União, que continuava com seu próprio instituto. 
Associado à criação do INPS, o Governo Federal passou a cogitar que o SAT deveria sair da iniciativa privada e ser estatizado. Em 1967, a Lei ${ }^{\circ} 5.316$ definiu que o SAT deveria ser responsabilidade do INPS. (CORDEIRO; SARATE; CLEMENTE, 2005) Além de instituir o monopólio estatal do SAT, incorporando-o à PS, a Lei $\mathrm{n}^{\circ}$ 5.316, também trouxe outras mudanças relevantes: o conceito de acidente de trajeto, a ampliação do risco profissional e a implantação do programa de prevenção de acidentes e reabilitação, refletindo, assim, uma preocupação com a prevenção das causas dos acidentes. Com a promulgação desta lei, teve início no país a notificação de acidentes e doenças profissionais, através da implementação pela PS, de um formulário específico para notificação de acidente de trabalho:

O médico que primeiro atender a um acidentado do trabalho deverá comunicar à previdência social dentro de 72 (setenta e duas) horas a natureza e a provável causa da lesão ou doença e o estado do acidentado, bem como a existência ou não de incapacidade para o trabalho e, na primeira hipótese, a provável duração da incapacidade, fornecendo ao acidentado um atestado com esses elementos. (BRASIL, 1967, Art'19)

Na década de 70 a reparação previdenciária se ampliou, passando a abranger novas categorias de trabalhadores. Os benefícios foram estendidos, em 1971, aos trabalhadores rurais, em 1972, aos empregados domésticos, e em 1973, aos trabalhadores autônomos. (BRUMER, 2002) Em 1974, no contexto da ampliação do universo de pessoas que passavam a receber benefícios previdenciários, decorrente do aumento de trabalhadores segurados, associado à incorporação de segmentos sociais desassistidos e ao envelhecimento gradativo da população, foi criado o Ministério da Previdência e Assistência Social (MPAS). A idealização desse Ministério representou um marco na evolução histórica para a previdência, apesar do período autoritário marcado pelo regime militar em vigor no país. Essa mudança foi caracterizada pela intervenção cada vez mais determinante do Estado e a adoção do conceito de seguridade social, que passou a englobar saúde, assistência e previdência. Seguindo este novo ordenamento, constitui-se através da Lei no 6.439, de 1977, o Sistema Nacional de Previdência e Assistência Social (SINPAS). (BRASIL, 1977) Este órgão era destinado a integrar as atividades do seguro pecuniário, assistência médica e de gestão 
administrativa, financeira e patrimonial das entidades vinculadas ao MPAS. O SINPAS tinha a seguinte composição: o INPS, que cuidava da concessão e manutenção das prestações pecuniárias; o Instituto Nacional de Assistência Médica de Previdência Social (INAMPS), o qual tratava da assistência médica; a Fundação Legião Brasileira de Assistência (LBA), que prestava assistência social à população carente; a Fundação do Bem-Estar do Menor (FUNABEM), que promovia a execução da política do bem-estar social do menor; a Empresa de Processamento de Dados da Previdência Social (DATAPREV), que era responsável pelo processamento de dados da PS; o Instituto da Administração Financeira da Previdência Social (IAPAS), que era responsável pela arrecadação, fiscalização, cobrança das contribuições e outros recursos e administração financeira; a Central de Medicamentos (CEME), que era responsável pela distribuição dos medicamentos. Fica assim evidente, a complexidade que se tornou o trinômio de previdência social, saúde e seguridade social na estrutura do governo.

Posteriormente, com a democratização e a elaboração da Constituição de 1988, ocorreu uma ampliação do conceito de seguridade social, que foi saudada como uma das maiores conquistas do direito social brasileiro. (CORDERO, 2005) A nova Constituição do Brasil incorporou o conceito de seguridade social nos moldes recomendados pela Convenção n¹02/1952 da Organização Internacional do Trabalho (OIT).

O capítulo da seguridade social da Constituição de 1988 introduziu uma concepção mais abrangente de seguridade social, definida como um conjunto integrado de ações destinadas a assegurar os direitos relativos à saúde, à previdência e assistência social, que deveria ser organizada pelo Poder Público. (BRASIL, 1988) O sistema passou a acolher o conceito de que a sociedade (incluindo os empregadores) se solidariza com o indivíduo trabalhador, cuja situação, quando em dificuldades, deixa de ser problema individual para constituir-se em responsabilidade social, pública.

A Constituição Federal de 1988 trouxe ainda, grandes avanços na área do direito social ao trabalho, assegurando aos trabalhadores o direito à saúde, à higiene, à segurança, à cidadania, à dignidade da pessoa humana, e aos valores sociais do trabalho e da livre iniciativa. (BRASIL, 1988) Destacam-se os Arts. $6^{\circ}$ e $7^{\circ}$, que incluem a proteção da saúde e do trabalhador, mais especificamente Art. $7^{\circ}$, em seu item XXVIII: 
"[...] seguro contra acidentes do trabalho a cargo do empregador, sem excluir a indenização a que este está obrigado, quando incorrer em dolo ou culpa". (BRASIL, 1988)

A Lei $n^{\circ} 8.213 / 91$ regulamentou a finalidade e os princípios previdenciários básicos e definiu, que independente da comprovação de dolo ou culpa, o auxilio acidente, que é financiado com recursos da alíquota recolhida do SAT, será concedido e pago pela previdência. (BRASIL, 1991a) Porém, apesar da ampliação da cobertura do SAT, nem todos os que contribuíam para a previdência tinham direito à sua cobertura, pois a Lei Federal n 8.213/91 e o Decreto n 3.048/99 excluíam dos benefícios do SAT as seguintes categorias: empregados domésticos, empresários, trabalhadores autônomos e trabalhadores avulsos.

No âmbito da mudança conceitual da previdência, a partir da Constituição de 1988, qualquer pessoa, mesmo que não esteja exercendo atividade remunerada, pode contribuir para a previdência. E neste sentido, a Previdência Social passou a ser considerada um seguro social que objetiva reconhecer e conceder direitos aos seus segurados. Para ter direito a esse seguro é preciso que o cidadão contribua (princípio contributivo), havendo o reconhecimento e concessão de direitos, ocorrerá pagamento de benefício previdenciário, que substituirá a renda do trabalhador contribuinte.

Em 1990, o INPS passou a se denominar Instituto Nacional de Seguridade Social (INSS) e foi fundido com o IAPAS, passando a ter como atribuições básicas a arrecadação, administração e pagamento de benefícios. Neste mesmo ano, com a Lei $\mathrm{n}^{\circ} 8.080 / 90$, o INAMPS foi absorvido pelo MS, sendo criado o SUS. Com estas mudanças a assistência à saúde foi definitivamente separada da OS. (BRASIL, 1990)

A notificação de acidente e doença do trabalho também sofreu reformulações e, baseado no princípio contributivo, foi aprovado o Regulamento Geral da Previdência Social (RGPS). (BRASIL, 1991a) Este definiu que benefícios previdenciários consistem em prestações pecuniárias pagas aos segurados ou aos seus dependentes, de forma a atender à cobertura dos eventos de doença, invalidez, idade avançada, maternidade, salário-família e auxílio-reclusão para os dependentes dos segurados de baixa renda, e pensão por morte do segurado, homem ou mulher, ao cônjuge ou companheiro e dependentes. Atualmente, existem 95 tipos de benefícios previdenciários concedidos através do INSS, 
que são codificados da seguinte forma: B21, B31, B32, B36, B91, B92, B93, B94 (sendo estes últimos de natureza acidentária).

O RGPS ratificou que, ao se afastarem do trabalho, os filiados ao RGPS deveriam buscar amparo através do INSS. Este concede benefício de forma a atender à cobertura dos eventos de doenças, que causem incapacidade para o trabalho com finalidade de compensação salarial. Os benefícios são concedidos após avaliação realizada pela perícia médica do INSS. O benefício previdenciário se inicia no $16^{\circ}$ dia consecutivo de afastamento, para aqueles segurados vinculados ao mercado de trabalho formal (cabendo ao empregador o pagamento dos 15 dias iniciais). (BRASIL, 1991a) Para os demais segurados, o benefício previdenciário terá início na data definida como o princípio da incapacidade, conforme sua última atualização em 2010. (BRASIL, 2010) Associado aos princípios do RGPS, em 1997 foi promulgado o Decreto $n^{\circ} 2.172 / 97$, que regulamentou os benefícios e estabeleceu limites (máximo e mínimo) para multas pela não emissão da Comunicação de Acidente do Trabalho - CAT. Este decreto foi revogado em 1999, pelo Decreto no 3.048/99, sem perda da regulamentação anterior. (BRASIL, 1999)

Compete à perícia médica do INSS avaliar a incapacidade laborativa e estabelecer o nexo causal entre acidente e/ou doença relacionada com o trabalho, ou seja, estabelecer a relação entre acidente e/ou doença profissional ou do trabalho e a existência de agente causador do agravo na atividade exercida. O estabelecimento do nexo no âmbito da PS se relaciona com conceito de incapacidade laborativa:

É a impossibilidade temporária ou definitiva do desempenho das funções específicas de uma atividade ou ocupação, em consequência de alterações morfopsicofisiológicas provocadas por doença ou acidente, para o qual o examinado estava previamente habilitado e em exercício; O risco de vida para si ou para terceiros, ou de agravamento, que a permanência em atividade possa acarretar, está implicitamente incluído no conceito de incapacidade, desde que palpável e indiscutível. (BRASIL, 1999)

A responsabilidade está bem definida, uma vez que independente da comprovação do dolo ou culpa do empregador pelo acidente, a compensação será paga pela PS. Neste fato reside a importância dos recursos oriundos do SAT, pois este se constitui em seguro obrigatório, custeado pelos empregadores, que se destina exatamente a custear os benefícios previdenciários e o auxilio acidente, e desta forma, fazer face 
aos riscos dos processos produtivos no que se refere à ocorrência de doenças profissionais e acidentes de trabalho.

O SAT, no ano de 1991, sofreu uma importante mudança com a Lei $\mathrm{n}^{\circ} 8.212 / 91$. (BRASIL, 1991b) Com isso, as alíquotas passaram a ser definidas de acordo com uma pré-determinada graduação de riscos, assim o recolhimento passou a ser baseado em alíquotas fixadas em razão do grau de risco da atividade preponderante do contribuinte. Alíquota de $1 \%$ para risco leve, de $2 \%$ para risco médio, e de $3 \%$ para risco grave. Posteriormente, a Lei no 10.666 de 2003, modificou estas alíquotas com a introdução do Fator Acidentário Previdenciário (FAP). Em 2007, o FAP foi regulamentado pelo Decreto $n^{\circ}$ 6.042/07, com mecanismo definido pelo Decreto n ${ }^{\circ}$ 6.042/07, em seu Art.14:

Poder Executivo regulamentará a questão da redução ou incremento do SAT, em razão do desempenho da empresa em relação à respectiva atividade econômica, fixando que a variação da alíquota do SAT básica será feita a partir do Fator Acidentário Previdenciário. (BRASIL, 2007b)

Neste contexto, instituiu-se, a partir da Lei $\mathrm{n}^{\circ} 11.430$ (BRASIL, 2006), uma nova metodologia para estabelecer nexo entre trabalho e doença, para fins de concessão de benefícios previdenciários. Desse modo, o benefício concedido poderá ser caracterizado como B31 (auxílio-doença previdenciário) ou como B91 (auxílio-doença acidentário). O benefício da espécie B91 relaciona-se à ocorrência de acidentes de trabalho e doenças causadas ou relacionadas ao exercício profissional. O beneficio da espécie B31 é concedido pelo INSS aos segurados afastados do trabalho por conta de agravos à saúde de natureza geral, ou seja, excluindo-se acidentes ou doenças relacionadas com o trabalho. (BOFF; LEITE; AZAMBUJA, 2002) Até março de 2007 para obtenção do benefício B91, os segurados acometidos por acidentes e doenças do trabalho necessitavam apresentar uma CAT, para provar que o acidente ou doença foi decorrente do trabalho ou agravada por este. A validade das informações da CAT dependia, principalmente, do completo e exato preenchimento do formulário, tendo em vista que as informações nele contidas eram de cunho previdenciário, estatístico, epidemiológico, trabalhista e social. (OLIVEIRA, 2008)

Com a implantação do Nexo Técnico Epidemiológico Previdenciário (NTEP) em 2007, inaugura-se outra modalidade para o 
estabelecimento do nexo entre trabalho e doença. Em funcionamento nos sistemas informatizados da PS para o reconhecimento do direito do trabalhador ao benefício previdenciário acidentário (B91), esta nova modalidade (NTEP) permite com que o trabalhador não dependa apenas da apresentação da CAT para a percepção deste benefício (B91).

O Nexo Técnico Epidemiológico está baseado em um sistema de informação no qual ocorre o cruzamento das informações do código da Classificação Internacional de Doenças (CID), $10^{a}$ edição, e código da Classificação Nacional de Atividade Econômica (CNAE), apontando uma forte probabilidade de existência de nexo entre doença e trabalho, que está baseada no excesso de casos de algumas patologias no ramo de atividade econômica a que pertence o trabalhador. (OLIVEIRA, 2008)

O NTEP começou a vigorar em 01/04/2007 e, a partir deste momento, a perícia médica do INSS passou a adotar uma nova metodologia para caracterização da natureza dos benefícios concedidos por acidentes e/ou doença relacionadas ao trabalho. Até a regulamentação do NTEP, a CAT foi instrumento fundamental para notificação de acidentes do trabalho e doenças profissionais.

\section{Os nexos entre doença e trabalho no âmbito da previdência social}

Atualmente, o nexo entre doença e trabalho, de acordo com a Instrução Normativa IN/PRES n ${ }^{\circ} 31$, de 11/09/2008, pode ser caracterizado por meio de três alternativas: Nexo Profissional, Nexo Individual e NTEP. (BRASIL, 2008)

O Nexo Profissional pode ser considerado um Nexo Presuntivo, e está baseado nas listas A e B que foram incorporadas ao anexo II do Decreto $n^{0}$ 3.048/99. (BRASIL, 1999) O Nexo Profissional está fundamentado nas listas A e B do Decreto $n^{\circ}$ 3.048. As listas A e B foram elaboradas devido a uma necessidade de atualização e padronização em relação às condições de risco que afetam a saúde dos trabalhadores e as doenças relacionadas com o trabalho, pois a falta de atualização e padronização vinha contribuindo para o surgimento de conflitos na esfera judicial entre os segurados, PS e empregadores. (MENDES, 2005)

A lista A, relaciona os agentes etiológicos ou fatores de risco de natureza ocupacional com doenças causalmente relacionadas com os 
respectivos agentes ou fatores de risco (denominadas e codificadas segundo a CID-10). Está organizada na forma de uma tabela de entrada por agente, por exemplo: Asbestos (agente patogênico) e Mesotelioma de pleura CID C45.0 (doença) sendo considerada uma lista de doenças profissionais. (MENDES, 2005)

A lista $\mathrm{B}$ relaciona a doença com os agentes etiológicos ou fatores de risco de natureza ocupacional. Essa lista tem dupla entrada de doenças do trabalho ou mesopatias, pois relaciona as condições específicas em que o trabalho é executado ou prestado e a ocorrência da doença. Por exemplo: síndrome cervicobraquial (doença) e exposição a posições forçadas, gestos repetitivos e vibrações localizadas (fator de risco de natureza ocupacional). (MENDES, 2005) A partir da adoção do NTEP, as listas A e B também passaram a fazer parte dos sistemas informatizados da PS, tornando a caracterização do benefício como acidentário mais ágil.

O Nexo Individual é fundamentado em laudos que comprovem condições especiais de trabalho capazes de causar o adoecimento, mas que não constam nas listas A e B. O Nexo Individual está baseado em uma avaliação pormenorizada do perito médico do INSS e em laudos que comprovem condições especiais de trabalho capazes de causar o adoecimento, mas que não constam nas listas A e B. Sempre que houver comprovação da efetiva exposição do trabalhador aos agentes nocivos, e sendo possível constatar a associação entre a profissiografia e a doença, o Nexo Individual poderá ser aplicado.

O NTEP é baseado em critérios epidemiológicos, em que doenças com maior prevalência em determinados CNAE (ramos econômicos) em relação a outros, passaram a ser consideradas presumivelmente ocupacionais. A lista de associações CID-CNAE referente ao NTEP passou a constar da lista C do anexo II do Decreto no 3.048/99. (BRASIL, 1999)

Procedimentos e rotinas referentes ao NTEP, Nexo Individual e Nexo Profissional foram inicialmente definidos na Instrução Normativa $\mathrm{n}^{\circ} 16$, em 2007, que foi substituída no ano seguinte, para finalmente constarem da Instrução Normativa IN/PRES n ${ }^{\circ} 31$, atualmente em vigor. (BRASIL, 2008)

A adoção do NTEP e o Nexo Profissional são considerados como uma presunção legal de que a doença sofrida pelo trabalhador pode ser 
de natureza ocupacional, invertendo assim o ônus da prova. Se antes o trabalhador tinha que comprovar que a sua doença fora ocasionada pelo trabalho, agora cabe ao empregador demonstrar que a doença não possui qualquer relação com o trabalho. A finalidade da presunção acolhida pela lei é facilitar o procedimento de nexo do acidente e da doença ocupacional pela vítima. Considera-se então, uma medida normativa decisiva para superar a precariedade de condições de prova dos trabalhadores acometidos por acidentes e doenças ocupacionais, pois representam a parte mais fraca e com menores condições de produção de nexo por conta da debilidade técnica, econômica e jurídica. Por outro lado, a capacidade de prova do empregador é muito maior, pois este detém todas as informações ambientais do local de trabalho e seus efeitos na saúde do trabalhador, tendo melhores condições de prova. Assim, quando o empregador discorda do nexo presuntivo, a nova legislação considera que ele detém aptidão para produzir a prova de inexistência do nexo causal. O NTEP reduz o estigma de injusta, a burocracia excessiva e ineficiente da Previdência Social que prejudicava significativamente a concessão de benefícios às vítimas de acidentes e doenças do trabalho. (OLIVEIRA, 2008)

Após adoção do NTEP, o total de benefícios classificados como acidentários pelo INSS passou a ser formado por benefícios com e sem CAT registrada. O quantitativo total dos acidentes registrados manteve esta lógica constituída pelos acidentes informados através da CAT e benefícios acidentários para os quais não há CAT informada.

\section{Seguro de acidentes de trabalho e sua relação com o nexo técnico epidemiológico previdenciário}

A adoção do NTEP e concessão de benefícios acidentários se relacionam com o SAT, importante fonte de custeio da Seguridade Social, que financia principalmente os benefícios concedidos através do INSS para eventos advindos dos riscos ambientais do trabalho como acidentes e doenças do trabalho e aposentadorias especiais. O SAT se baseia na tarifação coletiva das empresas, calculada sobre o total das remunerações pagas aos segurados empregados e trabalhadores avulsos. 
As alíquotas do SAT são definidas pela classificação de riscos das empresas e o cálculo funciona de acordo com o Decreto $\mathrm{n}^{\circ} 3.048 / 99$, que gradua o risco em conformidade com as atividades que realizem de forma preponderante. (BRASIL, 1999) A atividade preponderante é aquela que conta com o maior número de empregados e trabalhadores avulsos, levando-se em consideração todos os estabelecimentos da empresa. Assim, as empresas são agrupadas conforme a subclasse da CNAE em uma gradação de riscos: risco leve, que corresponde ao grupo de empresas cuja alíquota de SAT é de $1 \%$; risco médio, que corresponde ao grupo cuja alíquota do SAT é de $2 \%$; risco grave, que corresponde ao grupo com a alíquota de $3 \%$. A gradação de risco das empresas é revisada a cada três anos, com objetivo de verificar o grau de acidentalidade de cada empresa dentro de um determinado grupo de CNAE. A gradação de risco sugere a probabilidade de o processo produtivo de determinado grupo de empresas pertencentes àquela subclasse da CNAE adoecer mais ou menos. (OLIVEIRA, 2008)

Em fevereiro de 2007 a PS publicou o Decreto $n^{\circ} 6.042$, que regulamentou o Fator Acidentário de Prevenção (FAP), e com este, uma nova metodologia para fixação das alíquotas do SAT. (BRASIL, 2007b) O FAP foi implementado pela PS em janeiro de 2010.

O FAP é um fator de flexibilização, um multiplicador, que varia de 0,5 a 2 pontos, que é aplicado às alíquotas de $1 \%, 2 \%$ ou $3 \%$ da tarifação coletiva por subclasse econômica das empresas, incidentes sobre a folha de salários das empresas para custear aposentadorias especiais e benefícios decorrentes de acidentes de trabalho. A aplicação deste fator estabelece uma tarifação individual, através da flexibilização do valor das alíquotas de cada empresa, podendo ser reduzidas pela metade ou elevadas ao dobro. (BRASIL, 2007b)

O cálculo do valor de FAP a ser aplicado na alíquota do SAT de cada empresa será definido de acordo com os índices de frequência, gravidade e custos dos benefícios. Os índices são comparados com os perfis das empresas da mesma atividade econômica, CNAE, definindo então, o valor do fator multiplicador (FAP). O FAP será maior na medida em que forem mais frequentes, graves e custosos, os benefícios gerados por determinada empresa, quando comparados com empresas de um mesmo grupo da CNAE. (CORRÊA FILHO, 2005) Os indicadores de frequência, gravidade e custo são elaborados a partir do conceito que a 
morbidade mais frequente e que agrava determinado ramo econômico, ou grupo de empresas, é atributo daquela modalidade de trabalho e de produção. (CORRÊA FILHO, 2005)

As bases técnicas do FAP consideram as seguintes fontes de dados para os cálculos dos índices de frequência, de gravidade e de custo: registros da CAT relativos a cada acidente ocorrido; registros de concessão de benefícios acidentários que constam nos sistemas informatizados do INSS concedidos a partir de abril de 2007; dados dos vínculos empregatícios da CNAE, número de empregados, a massa salarial, os afastamentos, as alíquotas de $1 \%, 2 \%$ ou $3 \%$, bem como valores devidos ao Seguro Social; expectativa de sobrevida do segurado obtida a partir da tábua completa de mortalidade construída pelo Instituto Brasileiro de Geografia e Estatística - IBGE. (BRASIL, 2007b)

$O$ índice de frequência indica a incidência da acidentalidade em cada empresa em determinado período de tempo e inclui todos os acidentes registrados mediante CAT e benefícios acidentários estabelecidos a partir de nexos técnicos. (BRASIL, 2007b) Para realizar o cálculo deste índice são consideradas todas as ocorrências acidentárias: auxílio doença acidentário (B91), aposentadoria por invalidez acidentária (B92), pensão por morte acidentária (B93), auxílio acidente acidentário (B94) e CAT. O índice de frequência é calculado através da seguinte fórmula: índice de frequência é igual ao número de acidentes registrados em cada empresa, somados com os benefícios acidentários sem CAT vinculada, concedidos via nexo técnico, dividido por número médio de vínculos e multiplicado por mil.

O índice de gravidade indica a gravidade das ocorrências acidentárias em cada empresa. Para cálculo deste índice são computados todos os casos relacionados às quatro modalidades de ocorrências acidentárias, sendo atribuídos pesos diferentes para cada tipo de afastamento em função da gravidade da ocorrência. O benefício de pensão por morte acidentária tem peso maior de 0,50. Para os outros benefícios, os pesos são: aposentadoria por invalidez com 0,30; auxílio doença acidentário com 0,10; e auxílio acidente acidentário com o peso também atribuído de 0,10 . O índice de gravidade é obtido através da seguinte fórmula: índice de gravidade é igual ao quantitativo de auxílio doença por acidente (B91) multiplicado por 0,1 , somado ao quantitativo de aposentadorias por invalidez acidentária (B92), multiplicado por 0,3, somado ao quan- 
titativo de pensões por morte acidentárias (B93), multiplicado por 0,5 e somado ao quantitativo de auxílio-acidente (B94), multiplicado por 0,1, dividido pelo número médio de vínculos e multiplicado por mil. (BRASIL, 2007b)

O índice de custo representa o custo dos benefícios acidentários pagos pelo INSS. Para o cálculo deste índice são computados os valores pagos pelos benefícios acidentários. No caso do auxílio doença acidentário (B91), o custo de beneficio é calculado baseado no tempo de afastamento, meses e fração de mês, do trabalhador dentro do período de cálculo do FAP. Nos casos dos benefícios de aposentadorias por invalidez acidentária (B92), pensões por morte acidentárias (B93) e auxílio acidente acidentárias (B94), os custos são calculados através de uma projeção da expectativa de sobrevida a partir da tábua completa de mortalidade do IBGE, para toda a população brasileira, considerando-se a média nacional única para ambos os sexos. O cálculo do índice de custo é obtido pela seguinte fórmula: índice de custo igual ao valor total de benefícios dividido pelo valor total de remuneração paga pelo estabelecimento aos segurados multiplicado por mil. (BRASIL, 2007b)

Após o cálculo dos índices de frequência, de gravidade e de custo, são atribuídos os percentis de ordem para as empresas, por subclasse da CNAE, para cada um desses índices. As empresas que obtiverem menores índices de frequência, gravidade e custo de acidentes e doenças do trabalho, dentro daquela subclasse da CNAE, recebem o menor percentual; por outro lado, empresas com maiores índices recebem o percentual máximo. Quando a empresa não apresentar qualquer registro de acidente ou doença do trabalho, seus índices de frequência, gravidade e custo serão nulos; deste modo seu FAP será de 0,5, e consequentemente, sua alíquota do SAT será reduzida à metade.

O banco de dados gerado pela adoção do NTEP coleta os benefícios por incapacidade, indicando quais CNAE geraram mais benefícios acidentários. Desta forma, a adoção do NTEP possibilita a criação de um banco de dados consistente para o cálculo do FAP, estabelecendo uma relação de causalidade entre CNAE e doença que gerou beneficio. (OLIVEIRA, 2008)

Este mecanismo de flexibilidade do FAP poderá trazer modificações positivas no âmbito da proteção à saúde do trabalhador, pois permite que empresas com menos acidentes e doenças relacionadas com 
o trabalho sejam privilegiadas com uma redução na alíquota do SAT. (OLIVEIRA, 2008) Desta forma, o FAP poderá reduzir em até 50\% o imposto devido por empresas que reduzam a ocorrência de acidentes e doenças em seus trabalhadores. Poderá, também, aumentar em até duas vezes as alíquotas nos casos das empresas que apresentem indicadores de morbidade previdenciária piores que aqueles de seu próprio ramo de atividade econômica ou mais frequentes, graves e custosos que os demais setores produtivos de outros códigos de atividade econômica. (CORRÊA FILHO, 2005) O FAP passa a funcionar como um indicador de acidentes e doenças relacionadas com o trabalho das empresas. (OLIVEIRA, 2008)

Espera-se que a aplicação do FAP amplie a cultura da prevenção dos acidentes e doenças do trabalho entre as empresas e forneça subsídios para a estruturação do Plano Nacional de Segurança e Saúde do Trabalhador (PNSST), que vem sendo elaborado mediante a articulação dos Ministérios do Trabalho, Previdência e Saúde.

\section{Implantação do nexo técnico epidemiológico previdenciário: tecnologia da informação versus gestão da informação}

O principal objetivo da gestão da informação é identificar e potencializar informações estratégicas para a organização. A gestão da informação requer um processo de aprendizagem e adaptação ao ambiente, tanto externo quanto interno, por este motivo é fundamental o fluxo ininterrupto de informações, coleta e análise das mesmas para se chegar ao conhecimento e subsidiar a tomada de decisão. (ANDRADE, 2006) No caso da adoção do NTEP, a maior ênfase do processo é dada às informações provenientes do ambiente externo, que são coletadas, analisadas e monitoradas no ambiente interno. Com isso, a saúde dos trabalhadores e os agravos relacionados ao trabalho poderão ser monitorados pela Previdência por meio da gestão de informações estratégicas geradas pela adoção do NTEP.

Nesta perspectiva, a metodologia derivada da adoção do NTEP, enquanto Tecnologia da Informação vem provocando grandes mudanças no contexto organizacional da instituição, representada pela necessida- 
de de implantação de novos modelos e políticas de gestão no serviço público. Verifica-se, com isso, mudanças político-administrativas de inovação e modernização, que têm sido amplamente discutidas em virtude da emergente necessidade de otimização de resultados, associados à incessante busca por transparência na gestão pública, especialmente nos setores de saúde e previdência social. A adoção do NTEP, enquanto tecnologia da informação, enfoca a relação e reparação previdenciária (auxílios, indenizações, seguros) e associa às políticas de saúde pública de prevenção dos agravos à saúde da população trabalhadora.

Dentre os benefícios que poderão ser gerados pela adoção do NTEP, destacam-se a abordagem preventiva baseada no perfil epidemiológico da população trabalhadora, facilitando o diagnóstico dos fatores de risco condicionantes e determinantes para um grupo populacional específico e o reconhecimento, a partir das análises sistemáticas de dados gerados pela adoção do NTEP, de novos agravos ocupacionais. Isso contribuirá para divulgação de informações mais fidedignas sobre a saúde da população trabalhadora, informações estas, que contribuirão para a formação profissional daqueles que lidam com saúde do trabalhador. No futuro, os sistemas e bases de dados gerados pela adoção do NTEP, poderão ser integrados e partilhados com os sistemas e bases de dados dos Ministérios do Trabalho, Meio Ambiente e Saúde, contribuindo para a estruturação da Rede Integrada de Informações em Saúde do Trabalhador.

O processo de adoção e difusão da metodologia derivada do NTEP enquanto tecnologia da informação e comunicação provocou fortes alterações no modo como a informação é transmitida. Isto levou às mudanças na organização dos ambientes de trabalho e no contexto organizacional da Previdência, a constituição de um importante instrumento de subsídio de decisão dos peritos médicos previdenciários em relação à notificação de acidentes e doenças do trabalho.

\section{A adoção do nexo técnico epidemiológico previdenciário e a política nacional de segurança e saúde do trabalhador}

A Política Nacional de Segurança e Saúde do Trabalhador (PNSST) está inserida na política para o setor saúde envolvendo a relação entre 
Estado e Sociedade Civil. A saúde do trabalhador tem como objeto as relações entre trabalho e saúde, com o objetivo de desenvolver ações de vigilância, controle e prevenção de riscos, voltadas para promoção, proteção e recuperação da saúde do trabalhador (BRASIL, 2011).

A saúde dos trabalhadores é condicionada por fatores sociais, econômicos, tecnológicos e organizacionais relacionados ao perfil de produção e consumo, além de fatores de risco de natureza física, química, biológica, mecânica e ergonômica presentes nos diversos processos de trabalho. (SANTANA et al., 2006)

O campo do conhecimento voltado para saúde do trabalhador constantemente se altera, pois surgem novos objetos de estudo que incluem mudanças tecnológicas e organizativas dos processos de trabalho, reconhecimento de nexos causais entre trabalho e doença, diagnóstico de causa dos agravos à saúde, reconhecimento de novas doenças profissionais, controle ou eliminação de novos riscos dos ambientes laborais. (MINAYO-GOMEZ, THEDIM-COSTA, 1997) Assim, os estudos da saúde do trabalhador estão cada vez mais voltados para intervenções coletivas em uma perspectiva multicausal, com ênfase na prevenção, modificando assim, as interpretações da relação trabalho-saúde e as formas de intervenção nos ambientes de trabalho. Neste contexto merecem destaque as ações de trabalhadores, sindicatos, técnicos da área de vigilância e saúde do trabalho, legisladores e instituições acadêmicas. (MINAYO-GOMEZ, THEDIM-COSTA, 1997)

No Brasil existem várias instituições públicas com atribuições de intervenção na área de saúde do trabalhador. Historicamente, a política de Saúde do Trabalhador sempre sofreu com a falta de articulação entre estas diversas instituições, devido a uma multiplicidade e superposição de ações na área. Deste modo, na $8^{a}$ Conferência Nacional de Saúde, realizada em março de 1986, após um amplo debate, surgiram os primeiros eixos norteadores da PNSST com o objetivo de promover atenção integral à saúde do trabalhador. Posteriormente, na $2^{\text {a }}$ Conferência Nacional de Saúde do Trabalhador, o fórum definido na IX Conferência Nacional de Saúde, em 1992, teve como tema central a construção da PNSST.

No âmbito da saúde, a Portaria n 1.125/05 explicitava os propósitos da política de saúde do trabalhador para o SUS, que seriam: a promoção da saúde e a redução da morbimortalidade dos trabalhadores, 
implementação de ações integradas, intra e intersetorialmente, de forma contínua, sobre os determinantes dos agravos decorrentes dos modelos de desenvolvimento e processos produtivos, com a participação de todos os sujeitos sociais envolvidos. (BRASIL, 2005) Com o objetivo de realizar estas ações e fortalecer a PNSST no SUS, foi criada, em 19 de setembro de 2002, através da Portaria $n^{\circ} 1.679$, do Governo Federal, a Rede Nacional de Atenção Integral à Saúde do Trabalhador (RENAST). Esta tem por objetivo articular, no âmbito do SUS, ações de prevenção, promoção e recuperação da saúde dos trabalhadores urbanos e rurais, independentemente do vínculo empregatício e tipo de inserção no mercado de trabalho. (BRASIL, 2002) Com a RENAST, vislumbrava-se uma boa perspectiva de apoio institucional, aporte de recursos para viabilizar ações de saúde do trabalhador na rede de saúde do SUS e o fortalecimento do controle social em saúde do trabalhador.

Atualmente, a PNSST, além de estar diretamente relacionada com as políticas dos setores Trabalho, Previdência Social, Meio Ambiente e Saúde, apresenta interfaces com as políticas econômicas, de Indústria e Comércio, Agricultura, Ciência e Tecnologia, Educação e Justiça, em uma perspectiva intersetorial e transversal. No contexto atual, o objetivo desta política é abranger o maior número de trabalhadores possível, e por isto, considera trabalhadores todos os homens e mulheres que exercem atividades para sustento próprio e/ou de seus dependentes, qualquer que seja sua forma de inserção no mercado de trabalho, no setor formal ou informal da economia.

Estão incluídos nesse grupo todos os indivíduos que trabalharam ou trabalham, tais como: empregados assalariados, trabalhadores domésticos, avulsos, rurais, autônomos, temporários, servidores públicos, trabalhadores em cooperativas e empregadores, particularmente os proprietários de micro e pequenas unidades de produção e serviços, entre outros. Também são considerados trabalhadores aqueles que exercem atividades não remuneradas, participando de atividades econômicas na unidade domiciliar; o aprendiz ou estagiário e aqueles temporária ou definitivamente afastados do mercado de trabalho por doença, aposentadoria ou desemprego. (SANTANA et al., 2006)

O perfil de morbimortalidade dos trabalhadores se caracteriza pela coexistência de acidentes de trabalho típicos, doenças profissionais e doenças relacionadas ao trabalho. (SANTANA; NOBRE; WALDVO- 
GEL, 2005) A escassez e inconsistência das informações sobre a real situação de saúde dos trabalhadores sempre dificultou a definição de prioridades, o planejamento e alocação de recursos para ações da política Nacional de Saúde do Trabalhador, além de privar a sociedade de instrumentos importantes para melhoria das condições de vida e trabalho. (SANTANA et al, 2006) Nesse sentido, a importância da adoção do NTEP para política Nacional de Saúde dos Trabalhadores se relaciona ao reconhecimento do nexo entre acidentes, doenças e trabalho pela Previdência Social, que constitui um importante instrumento estatístico/epidemiológico de subsídio para o perfil de morte e adoecimento relacionado ao trabalho.

Apesar de todos estes avanços na legislação na área de Saúde do Trabalhador ainda existem ações não integradas e executadas por órgãos distintos e distanciados institucionalmente. A despeito de se atribuir ao SUS a responsabilidade pela assistência médica ao doente e ao acidentado do trabalho, pressupondo o atendimento deste na rede de saúde, as ações de reabilitação não foram totalmente incorporadas e são precariamente articuladas entre o SUS e a estrutura do INSS. As ações de fiscalização dos ambientes de trabalho continuam sendo primordialmente executadas pelo Ministério do Trabalho por meio da Superintendência Regional do Trabalho e Emprego - SRTE e pelo Ministério da Previdência Social, através do Instituto Nacional de Seguridade Social INSS, mas ainda falta uma articulação destas instituições com as ações da Vigilância Sanitária. O intercâmbio de informações entre o espaço social e a esfera administrativa sobre acidentes e doenças do trabalho ocasionado pela adoção do NTEP poderá proporcionar uma maior articulação das inovações institucionais com a sociedade, interações mais estreitas entre todas as esferas do Estado para a melhoria da saúde dos trabalhadores.

\section{Considerações finais}

A história da Previdência Social no Brasil mostra um longo processo de institucionalização do seguro acidentário, passando de empresas às categorias profissionais, para finalmente alcançar todo o mercado formal de trabalho pelo regime da Consolidação das Leis do Trabalho (CLT). De estrutura bipartidária, passou ao sistema tripartite com a in- 
trodução do Estado junto ao empregador e trabalhador. Nesse processo, o poder público assumiu o controle político da previdência e incorporou a evolução da noção de seguro para seguridade, ao tomar a saúde e a assistência social como objeto da proteção. Com a Constituição de 1988, a noção de seguridade emergiu como direito do cidadão e dever do Estado, estendendo-se a toda sociedade.

Nesse contexto, o seguro acidentário introduziu as modalidades de comunicação do evento doença e acidente, para desencadear os procedimentos periciais de caracterização da relação ou nexo com o trabalho. Momento marcante desse processo foi a introdução da CAT como documento de notificação obrigatória dos acidentes e doenças do trabalho para todo aquele pertencente ao mercado formal em regime CLT. A CAT sintetizava os nexos clínico, epidemiológico e administrativo necessários ao reconhecimento da doença ou acidente do trabalho. No entanto, o ônus desses procedimentos recaía sobre o trabalhador e impunha condições de subnotificação desses agravos. Todavia, estas notificações produziram informações epidemiológicas sobre um universo grande de trabalhadores, o que se constituiu em uma modalidade de inteligência, cujo uso gerencial possibilitou a estruturação de decisões capazes de conferir ao trabalhador nexos presuntivos de doenças do trabalho. Originou-se assim o NTEP, que proporcionou a inversão da lógica da prova, transferindo o ônus do contraditório para o empregador.

O NTEP resultou no aumento significativo do reconhecimento de doenças relacionadas ao trabalho, reduzindo significativamente a invisibilidade epidemiológica e o sofrimento do trabalhador na garantia dos seus direitos securitários. Mantém-se a CAT, mas o próprio aumento das notificações pelo NTEP retroalimenta as informações epidemiológicas, fortalece ainda mais a capacidade gerencial dos procedimentos de nexo presuntivo e subsídios às ações intersetoriais com o SUS e demais órgãos envolvidos na proteção do trabalhador. Há avanços ainda a serem feitos, principalmente em relação às patologias do trabalho e acidentes de categorias com difícil acesso ao sistema de saúde. No entanto, o NTEP indica que é possível aperfeiçoar a gestão pública com o uso adequado da informação, dos fundamentos de epidemiologia e dos princípios gerenciais que priorizam a garantia de direitos. Esse exemplo pode servir para outras instituições, na perspectiva de se construir uma Política de Saúde do Trabalhador efetiva, com ações de prevenção, 
promoção e recuperação da saúde dos trabalhadores urbanos e rurais, independentemente do vínculo empregatício e do tipo de inserção no mercado de trabalho.

\section{Referências}

ANDRADE, S. C. R. Processo de inclusão digital em rede empresarial do segmento de suprimentos industriais: utilização de tecnologias de informação e comunicação. Ciência da Informação, v. 35, n. 1, jan. - abr. , 2006

BOFF, M. B.; LEITE, D.; AZAMBUJA, M. I. Morbidade subjacente à concessão de benefício por incapacidade temporária para o trabalho. Revista Saúde Pública, São Paulo, v. 36, n. 3, jun. , 2002.

BRAGA, D. Acidente de trabalho com material biológico em trabalhadores da equipe de enfermagem do Centro de Pesquisas Hospital Evandro Chagas: um olhar da saúde do trabalhador. 2000. 75f. Dissertação (Mestrado em Ciências). Fundação Oswaldo Cruz, Escola Nacional de Saúde Pública, Rio de Janeiro, 2000.

BRASIL. Congresso Nacional. Lei no 6.439 de 01 de setembro de 1977, Institui o Sistema Nacional de Previdência e Assistência social, e dá outras providências. Brasília: Diário Oficial da União, 02 set. 1977.

. Instituto Nacional do Seguro Social. Instrução Normativa INSS/PRES no 31 de 10 de setembro de 2008, Dispõe sobre procedimentos e rotinas referentes ao Nexo Técnico Previdenciário, e dá outras providências. Diário Oficial da União, 11 set. 2008.

BRASIL. Ministério da Saúde. Organização Pan-Americana de Saúde. Doenças Relacionadas ao Trabalho. Manual de Procedimentos para Serviços de Saúde. Série A. Normas e Manuais Técnicos, Brasília, n. 114. 2001.

. Ministério da Saúde. Portaria no 1. 679/GM de 19 de setembro de 2002, Dispõe sobre a estruturação da rede nacional de atenção integral à saúde do trabalhador no SUS e dá outras providências. Disponível em: <http://dtr2001. saude. gov. br/sas/PORTARIAS/ Port2002/ Gm/GM-1679. htm. > Acesso em: 20 de novembro de 2011.

. Ministério da Saúde. Portaria no 1. 125/GM de 6 de julho de 2005, Dispõe sobre os propósitos da política de saúde do trabalhador para o SUS. Disponível em: <http://dtr2001. saude. gov. br/sas/PORTARIAS/ Port2005/GM/GM-1125. htm. > Acesso em: 20 de novembro de 2011. . Ministério da Previdência Social. Anuário Estatístico da Previdência Social. Brasília: MPS/DATAPREV, 2007 a. 
BRASIL. Ministério da Previdência Social. Instrução Normativa INSS/ PRES no 45 de 6 de agosto de 2010, Dispõe sobre a administração de informações dos segurados, o reconhecimento, a manutenção e a revisão de direitos dos beneficiários da Previdência Social e disciplina o processo administrativo previdenciário no âmbito do Instituto Nacional do Seguro Social - INSS. Diário Oficial da União, 11 ago. 2010.

. Presidência da República. Decreto-Lei no 4.682 de 24 de janeiro de 1923, Cria, em cada uma das empresas de estradas de ferro existentes no país, uma Caixa de Aposentadoria e Pensões para os respectivos empregados. Diário Oficial da União, 28 jan. 1923.

. Presidência da República. Decreto-Lei no 7.036 de 10 de novembro de 1944. Reforma da Lei Acidente de Trabalho. Diário Oficial da União, 13 nov. 1944. Disponível em: < http://www2.camara.leg. br/legin/fed/declei/1940-1949/decreto-lei-7036-10-novembro-1944389493-publicacaooriginal-1-pe.html >. Acesso em: 01 jan. 2012.

. Presidência da República. Lei no 3. 807 de 26 de agosto de 1960, Dispões sobre a Lei Orgânica da Previdência Social. Brasília: Diário Oficial da União, 05 set. 1960.

. Presidência da República. Lei no ${ }^{\circ}$ 5. 316 de 14 de setembro de 1967, Integra o seguro de acidentes do trabalho na previdência social, e dá outras providências. Brasília: Diário Oficial da União, 18 set. 1967.

. Presidência da República. Lei no 8. 080 de 19 de setembro de 1990, Dispõe sobre as condições para a promoção, proteção e recuperação da saúde, a organização e o funcionamento dos serviços correspondentes e dá outras providências. Diário Oficial da União, 20 set. 1990.

. Presidência da República. Lei no 8. 213 de 24 de julho de 1991, Dispõe sobre os Planos de Benefícios da Previdência Social e dá outras providências. Diário Oficial da União, 14 ago. 1991a.

BRASIL. Presidência da República. Lei no 8. 212 de 24 de julho de 1991, Dispõe sobre a organização da Seguridade Social, institui Plano de Custeio, e dá outras providências. Diário Oficial da União, 25 jul. $1991 b$.

. Presidência da República. Decreto n ${ }^{\circ}$. 611, de 21 de julho de 1992, dá nova redação ao Regulamento dos Benefícios da Previdência Social. Diário Oficial da União, 22 jul. 1992.

. Presidência da República. Decreto n ${ }^{\circ}$. 3. 048 de 06 de maio de 1999, Aprova o Regulamento dos Benefícios da Previdência Social, e da outras providência. Diário Oficial da União, 07 maio 99. 
BRASIL. Presidência da República. Lei no 11.430 de 26 de dezembro de 2006, Altera as Leis nos 8.213 , de 24 de julho de 1991, e 9. 796, de 5 de maio de 1999, aumenta o valor dos benefícios da previdência social; e revoga a Medida Provisória n ${ }^{\circ} 316$, de 11 de agosto de 2006; dispositivos das Leis $\mathrm{n}^{\text {os }} 8$. 213, de 24 de julho de 1991, 8. 444, de 20 de julho de 1992, e da Medida Provisória no 2. 187-13, de 24 de agosto de 2001; e a Lei n ${ }^{\circ}$ 10. 699, de 9 de julho de 2003. Diário Oficial da União, 27 dez. 2006.

. Presidência da República. Decreto no 6.042 de 12 de fevereiro de 2007, Altera o Regulamento da Previdência Social, aprovado pelo Decreto no 3. 048, de 6 de maio de 1999, disciplina a aplicação, acompanhamento e avaliação do Fator Acidentário de Prevenção - FAP e do Nexo Técnico Epidemiológico, e dá outras providências. Diário Oficial da União, 12 fev. 2007b.

. Presidência da República. Decreto n ${ }^{\circ} 7.602$ de 7 de novembro de 2011, Dispõe sobre a Política Nacional de Segurança e Saúde do Trabalhador - PNSST. Diário Oficial da União, 08 nov. 2011.

. Senado Federal. Constituição da República Federativa do Brasil de 1988. Brasília: Diário Oficial da União, 05 out. 1988.

BRUMER, A. Previdência social rural e gênero. Sociologias, Rio Grande do Sul, n. 7, p. 50-81, 2002.

CARNEIRO, L. S. Uma visão sistemática da previdência social. Revista de Direito, v. 11, n. 13, 2008.

CORDEIRO, R.; SAKATE, M.; CLEMENTE, A. P. Subnotificação de acidentes do trabalho não fatais em Botucatu. Revista Saúde Pública, São Paulo, v. 39, n. 2, abr. 2005.

CORRÊA FILHO, H. R. O Fator Acidentário Previdenciário como instrumento epidemiológico de controle de riscos do trabalho.

Revista Brasileira de Epidemiologia, v. 8, n. 4, dez. 2005.

MENDES, R. Conceito de patologia do trabalho. In: Mendes, R. (Org.).

Patologia do Trabalho. 2. ed. São Paulo: Atheneu, 2005. p. 48-92.

MINAYO-GOMEZ, C.; THEDIM-COSTA, S. A construção do campo da saúde do trabalhador: percurso e dilemas. Caderno Saúde Pública, Rio de Janeiro, v. 13, 2 jan. 1997.

OFFE, C. Trabalho: a categoria chave da sociologia? Revista Brasileira de Ciências Sociais. São Paulo, v. 4, n. 10, jun. 1989.

OLIVEIRA, P. R. Nexo Técnico Epidemiológico Previdenciário - NTEP e o Fator Acidentário de Prevenção - FAP: um novo olhar sobre a saúde do trabalhador. 2008. 240f. Tese (Doutorado em Ciências da Saúde). Faculdade de Ciências da Saúde, Universidade de Brasília, Brasília, 2008. 
RAMAZZINI B. As doenças dos trabalhadores.

2. ed. São Paulo: Fundacentro, 1999.

SANTANA, V. S.; NOBRE, L.; WALDVOGEL, B. Acidentes de trabalho no Brasil entre 1994 e 2004: uma revisão. Ciência Saúde Coletiva, Rio de Janeiro, v. 10, n. 4, p. 841-855, out. -dez. 2005.

SANTANA, V. S. et al. Acidentes de trabalho: custos previdenciários e dias de trabalho perdidos. Revista de Saúde Pública, São Paulo, v. 6, n. 6, p. 1004-1012, 2006. . Gravidade dos acidentes de trabalho atendidos em serviços de emergência. Revista Saúde Pública, São Paulo, v. 43, n. 5, p. 750-760, out. 2009.

SANTOS, M. Direito previdenciário. Rio de Janeiro: Saraiva, 2007. 